\title{
FEATURES OF THE ADMINISTRATIVE-TERRITORIAL DEVELOPMENT IN BULGARIA
}

\author{
Assoc. Prof. Dr. Kamen Petrov \\ Vice Dean in Faculty Management and Administration, Department Regional Development \\ University of National and World Economy, Sofia, Bulgaria
}

Article DOI: https://doi.org/10.36713/epra5498

\begin{abstract}
Knowledge of socio-economic processes for the realization of the state will determine the course and their division of the territory of the administrative-territorial and territorial units. Planning and construction of each administrative unit must meet the structural limits, requirements, parameters and characteristics peculiar to themselves socio-economic processes. Territorial unity and socio-economic development is implemented in line between the territorial scope of ATU, on the one hand, and the boundaries of socio-economic impact of public policies in the territories of another. It ranks among the administrative territorial unit active and important elements of the development of public relations.
\end{abstract}

KEY WORDS: territory, state, structure, administration, development

\section{INTRODUCTION}

In the modern nation-state, the administrativeterritorial structure is a key element of the organization of the state and public administration. Bulgaria is located in Southeast Europe and has a predominant local self-government. The region is an administrative territorial unit for conducting regional policy, implementing public administration at the local level and ensuring the concurrence of national and local interests.

Figure 1. Geographical position of Bulgaria

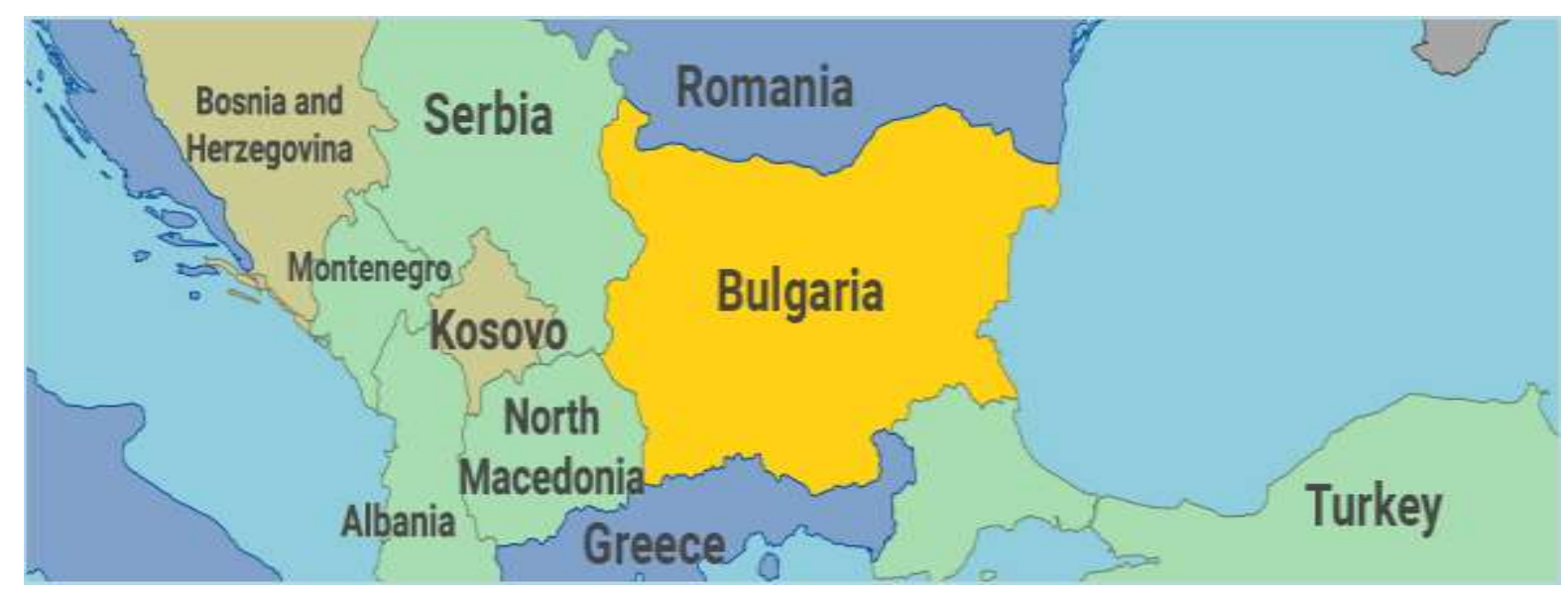

Source: Bulgarian Academy of Sciences, Geographical Institute

The territorial structure to a large extent determines the significance of all ongoing life processes in the state organism. It includes the division of the territory into administrative-territorial 
(ATE) and territorial units and (TE), determination of their hierarchy and subordination, so as to create conditions for targeted state influence through policies, imposition of standards and provision of services. Settlements and settlement formations are defined as territorial units (TE). The settlements are divided into towns and villages, indicating the order and conditions for their transformation.

The settlement formations are divided into national and local, indicating the order of their determination. A unified approach and general principles are applied in determining the main elements of ATE and TE - territory, borders, name, administrative center, population. The population takes part in the processes of administrative-territorial changes (ATP), applying forms of direct democracy. Alternative possibilities for the implementation of specific types of territorial changes are allowed. In this sense, the purpose of this article is to show the chronology of administrative-territorial changes in recent years and how they affect the regional development of the national territory. Moreover, in the Bulgarian state tradition the municipality is the main administrative-territorial unit in which the local self-government in the Republic of Bulgaria is carried out. For example, only in the last 40-50 years in the country reforms have been carried out in the municipalities and until 1979 there were 1389 municipalities. After the large-scale administrativeterritorial reform carried out in the period 1978-1979, the number of municipalities was reduced to 291 . After the change, mainly affecting the municipalities, the dynamics of changes decreased significantly in the next reform (1989-1999), related to the introduction of 28 districts, the number of municipalities is 265 .

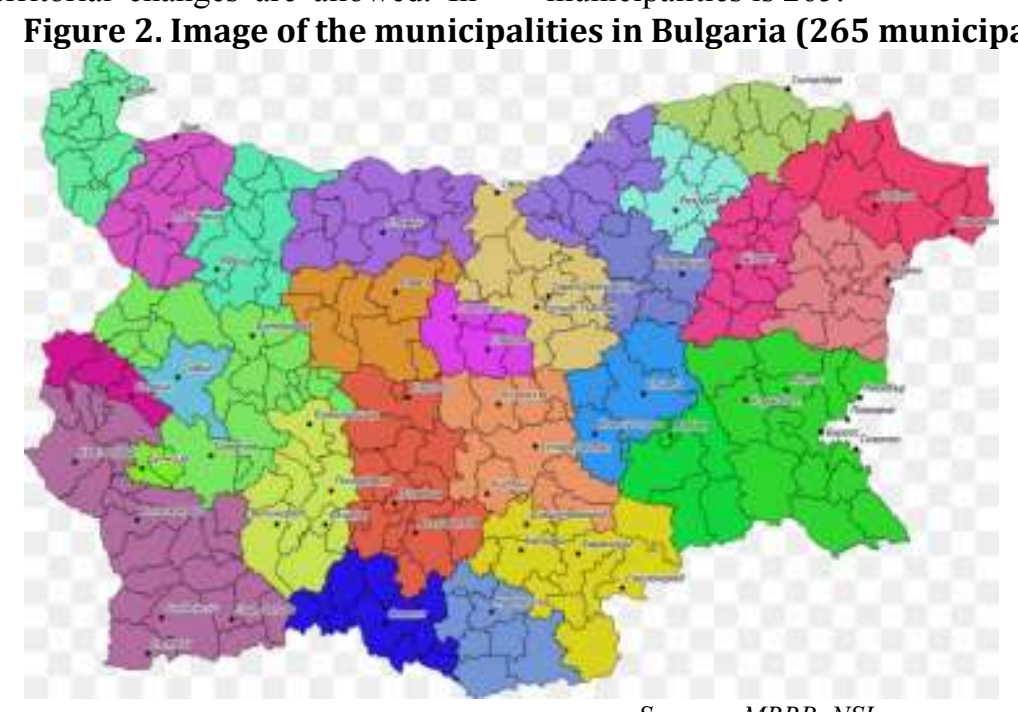

Sources: MRRB, NSI

With the adopted Law on Administrative and Territorial Organization of the Republic of Bulgaria (SATURB), the new foundation was built, but at the same time the debate was opened to fill the gaps and gaps in it, so changes and assessment of the administrative structure become necessary. The territorial and settlement structure is an activity of legal, economic and social subjects determined by the laws of the country, whose activity aims at creating favorable conditions for living, work and recreation of the population.. The need for urban development stems from the need to create a living environment and improvement of settlements so as to create favorable conditions for human development. Settlements as a basis for concentrating public activity are formed during the historical development of society. Influenced by the positive development of society and the development of productive forces. The settlements are created before the state and on their basis the state formations are created. In the beginning, villages and towns were considered as settlements. Subsequently, settlements and settlements are spoken of where there is active human activity, as a result of which the natural environment changes. This is also reflected in the Bulgarian legislation. For settlements and settlements are recognized holiday villages, resorts and industrial complexes, which have different factors and legal status. The factors that affect the settlement structure are in several categories. They are economic, political, geographical and social, type, structure and character of the population, as well as its distribution.

\section{Characteristics of the next administrative-territorial structure in the country}

The influence on the settlement structure shows various natural geographical factors such as relief, fuels, energy sources, forest resources, territories. In terms of relief, Bulgaria ranks among the countries with the most favorable conditions for rural development. It has a relatively equal position on the territory. Low lands are $31 \%$, hilly $-28 \%$. The 
average altitude is the most favorable for construction and public works, namely $470 \mathrm{~m}$. Water resources are unevenly distributed. At present, in the current Administrative-Territorial Organization (ATU) of the Republic of Bulgaria it can be characterized as stable. Unlike a number of countries in Europe, there is no process of fragmentation in Bulgarian municipalities. There are two types of administrative and territorial units - districts and municipalities, in accordance with the constitutional provisions [1]. The changes in the socio-economic relations of the country are protected by the constitutional protection of ATU. All constitutions adopted in the Third Bulgarian State determine the normative framework of the administrative-territorial organization of the country. On the other hand, the formed mayoralties from one or several settlements as independent administrative and territorial units (CATE) in the municipalities allow in Bulgaria to impose specific regulation and development of the local self-government and the administration of the population. With the increase of the population, districts have been formed in the Sofia Municipality and the two big cities over 300 thousand people, another issue is that depending on the administrative burden I consider it appropriate for the municipalities with a population of more than 125 thousand people to be able to form districts as administrative units. in them. The structure of the territory is a system of measures, acts and actions of factual legal nature, which aim to create regulatory conditions for the use of the earth's surface for work, recreation and rehabilitation of the population. The territories in the country are divided into groups according to different criteria. Through this division, the state determines which parts of its territory can be used for what purposes, regardless of their physical and geographical location. Until now, according to the law on territorial and settlement organization, there was one main division. It depended on the purpose of the territory [2].

Refers to urban and rural areas. It seeks to eliminate the delineation of urban and non-urban areas and to create a unified regime that depends only on the specifics of the territory and its purpose according to the adopted plans. There are several features of the legal characteristics of the structure of the territory. In the first place, all activities on the structure of the territory are subject to legal regulation. The Spatial Planning Act defines the territorial and land properties according to their main purpose. It is determined specifically by development schemes and development plans. Land properties are parts of the territory and their use depends on the nature and on the projections and prospects of the respective plans [3].

The first, main category is the so-called urban areas. They are used to meet the immediate needs of people related to work, leisure and recovery. The second next category are agricultural categories (territories). They cover arable land and often uncultivated land. The third category is forest areas. The fourth - protected areas. A territory acquires the character of protected in connection with its specific natural, historical, climatic or cultural features. The legislation allows for a change in the purpose of the territory. For this it is necessary to perform certain actions. In the first place it is important whether the construction event is planned for the respective territory or land property. This means that under this law only construction can be a reason for a change in the purpose of the territory. Another important condition is to have a detailed development plan in place. This means that this plan has been drawn up by the relevant competent authorities and the time limits for appeal have expired or have not been appealed. For the territories or parts of them, which for public, state and public property, it is not allowed to change the purpose. An exception can be made in the first place if there is a permit from the regional governor for state public property or from a general. Council for public common. Property. the structure of the territories and the specific purpose of each part of these territories depends on the provisions, which are normatively established by a development scheme and development plans. Within the territories there are separate plots of land. On the site of a plot there is talk of land. Legislation related to the structure of the territory gives a legal definition of this concept. This is the part of the territory that is defined by boundaries with the right of ownership and can be used in accordance with the norms contained in the plans. The land properties themselves can be grouped. This is done in territorial and development zones, which are determined in accordance with the general urban plans.Construction is allowed only after a detailed development plan has been approved and entered into force. The legislation is a legal definition of construction as a legal normative activity of the various legal entities. According to the law on spatial planning, construction is the location and view of buildings, structures, networks and facilities in land properties. Construction in separate territories is allowed under conditional procedures. It may be laid down in a detailed development plan or in several special laws.

In the modern world there are more than 190 state entities, and depending on their characteristics and structure, they determine the respective competencies of government and regulate the relationship between the state and citizens. In this regard, public administration is regulated by the basic laws of the countries or in other words by the Constitution of Bulgaria.Accordingly, the requirements for the development of the territories are determined by development schemes and plans in accordance with the current regulations. In the separate states according to the separate constitutions 
the level and character of the legal regulation of administrative-territorial structure is determined.

In most countries, the regulation of the administrative-territorial structure is at the constitutional, legal and by-law level. Territories with special territorial protection, including territories with specific characteristics, determined by the order of separate laws, may acquire a special regime of structure and control. The scope and mode of their device are determined by development schemes and plans. The territorial structure analyzes the current state of the settlement network, the problems and trends of the urban environment. The ratio between urban and rural population, territorial scope of urbanized and non-urbanized territories, depopulated settlements, unusable buildings, environmental problems related to urbanization, expansion of urban areas at the expense of agricultural land. Municipal and settlement network, number and type of settlements, density, density (altitude / 100 sq. Km.), Infrastructure provision.

The visualization (depiction) of the territorial structure in the separate territory reflects - the agricultural territories, the forest fund, the urbanized, protected and disturbed territories. Assessment of their condition and ratio, opportunities for development and improvement of this structure [4].

The comparative data for the Bulgarian municipalities by population and territory in the European context show that they are comparable with the medium-sized European municipalities. The quantitative characteristics for population and territory of the districts in Bulgaria refer them to the group of NUTS 3 units according to the European statistical categorization.

With a total territory of $111,001.9 \mathrm{~km} 2$ and a population of 7,336,710 people (March 30, 2012), the main parameters of the two types of administrative units (excluding the Sofia Municipality) for the districts: by population - an average of 240,264 people (out of 117,809 up to 707570 ), by territory an average of $4061.2 \mathrm{~km} 2$ (from 2023.0 to 7748.1 ). On average, about 10 municipalities (from 4 to 22) are included within one district. For the municipalities (excluding Sofia): by population - an average of 24,666 people (from 1,188 to 34,173 ), by territory - an average of $416.9 \mathrm{~km} 2$ (from 44.4 to 1,366.6). An average of 20 settlements are included in one municipality. In the social and economic development of the country an important feature in the grouping of districts and municipalities is the criterion population. According to the existing administrative units and their grouping of the districts by population, it brings to the fore the group of districts with a population of up to 200 thousand people. It covers 14 districts, followed by the group of districts with a population of 200 to 400 thousand people, which includes 11 districts. The grouping of municipalities by population distinguishes two groups of municipalities - the first includes municipalities up to 10 thousand people, and the second - from 10 to 30 thousand people. The first group covers 103 municipalities $(39 \%$ of all municipalities in the country). About $8.1 \%$ of the country's population live within this group of municipalities and these municipalities include $25 \%$ of the total territory of the country. The second group covers 112 municipalities ( $42 \%$ of the total number). The municipalities of this group inhabit $25.4 \%$ of the population, the territory of the municipalities included in it represents $46 \%$ of the territory of the country. The current 28 districts have been operational since the beginning of 1999 [7]. In practice, they reproduce the number and boundaries of the districts that existed until 1987. This change took place mainly under the pressure of society, as the nine districts created in 1987 could not control and effectively and efficiently exercise the powers assigned to them. Created with the means of the command-administrative approach, they were very different in terms of territory and population, as well as in terms of economic potential. During the period of their existence, they could not readjust the system of communications and relations with the former districts, to overcome the acute shortage of human resources, to control the processes of disintegration and restructuring of economic structures, to exercise effective control over the work of municipal selfgovernment bodies. . The automatic reproduction of the county model, created in 1961, also has its pros and cons [3].

\section{Administrative territorial changes and reforms in the municipalities of Bulgaria}

During the analyzed period the administrative and territorial structure of the country was enriched with nine new administrative-territorial units municipalities. All newly created municipalities (Primorsko, Dolna Banya, Gurkovo, Nikolaevo, Krichim, Perushtitsa, Stamboliyski, Kuklen and Sopot) are of the type "creation through separation". Seven of the changes were implemented in the period July 1997 - April 1998, the last change being the establishment of the municipality of Sopot in 2003. As in 2014, the case of Sarnitsa. The reason for the requested separation is the distance of $40 \mathrm{~km}$ to Velingrad. territorial change within the boundaries of the municipality of Velingrad and for the creation of a new municipality with an administrative center in the town of Sarnitsa. It will include 2 more villages Medeni Polyani and Pobit Kamak.

In the last 20 years after the adoption of the laws on territorial and administrative structure, changes have taken place with events "creation by merger", "creation by division", "creation by new administrative-territorial structure". There are four "donor" municipalities of new municipalities (Samokov, Maglizh, Rodopi and Karlovo) and most new municipalities $(44.4 \%)$ were created on the basis of separation from Rodopi municipality - Perushtitsa, 
Krichim, Stamboliyski and Kuklen. The municipalities of Gurkovo, Sopot and Nikolaevo are separated from the municipality of Maglizh and formed. The last established municipality of Sarnitsa was separated from the municipality of Velingrad in 2014. Within the analyzed period, twenty-four changes in the closure of municipalities were registered. However, all the changes are related to the introduction of the regions as constituent administrative-territorial units (SATU) in the city of Sofia and the closure of the existing 24 Sofia municipalities. . In the national register of settlements there are no common events with "closure upon merger", "closure upon division", "closure upon accession" and "flood". If we assume that the municipality as the main unit of local selfgovernment in Bulgaria is the bearer of the legal and organizational opportunities for citizen participation in government, so that a conclusion can be drawn that changes during this period leads to the development of local democracy and more. wide distribution of citizens in government [7].

Figure 3. Location of the municipalities in Bulgaria by development

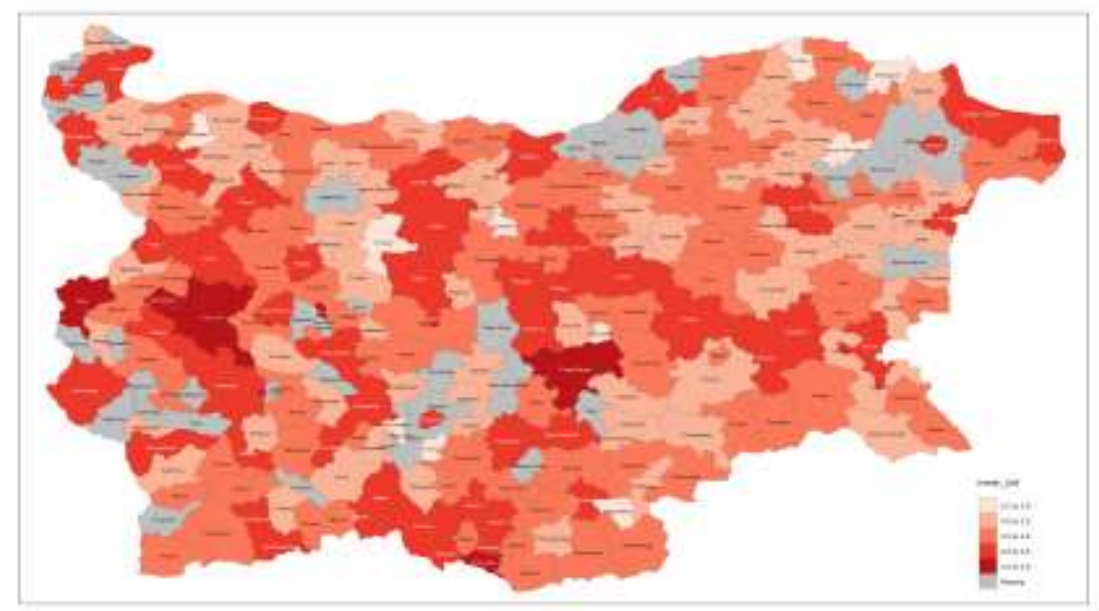

Source: NSI, MRRB

Analyzing the intensity and dynamics of the changes made at the municipal level in the period after the adoption of the law on territorial and settlement planning and especially after its amendment in 1998 (amended, SG No. 154/1998), it can be concluded that there is a relatively modern legislation, covering to a large extent the social processes in the field of territorial organization of the country. At the same time, it should be noted that the existing legislation does not address development processes, which is particularly important in a highly dynamic socio-economic environment, in particular demographic and urban change over the last ten years. Although slowed down, the tendency to increase the number of administrative units is oneway and reflects the irrationality of individual subjective decisions and some disparities in the territorial organization of the country in recent decades. Creation or closure of municipalities due to "merger", "division", "accession" and "deletion" are forms that are not used in practice to carry out administrative-territorial change at the municipal level. The use of some of these forms in the future should be encouraged by ensuring economic interest, using the tools available to the central government (eg relations with the national budget, access to resources from the Structural Funds, etc.). During the analyzed period there is no case of closure of a municipality. The comparative data for the Bulgarian municipalities by population and territory in the
European context show that they are comparable with the medium-sized European municipalities, which is considered as a favorable factor for their successful development and functioning. Therefore, improving the efficiency of territorial governance must be at the expense of the qualitative development of the decentralization process in the country, without questioning the established model as a whole. However, in a number of municipalities (especially individual municipalities, which currently do not meet the conditions for independent existence), there are negative trends in their condition, such as severely deteriorating demographic characteristics and processes, limited and constantly decreasing resource potential (including human and financial), weak economic development and low tax base. These are obstacles that severely limit their future development and raise questions related to taking measures to increase the efficiency of their existence. There is a tendency to attract the peripheral settlements from the composition of small and relatively less developed municipalities to larger municipalities. This is very pronounced in cases where the host municipality is also a regional center. It is necessary to make a careful analysis of the size of the administrative-territorial and territorial units in terms of efficiency, effectiveness of the services provided and the quality of local democracy, as well as the impact of possible change. In our country, in relation to the municipalities, the districts can do it, 
and in the case of the mayoralties and the settlements - the municipalities. For example, when a unit is judged to be too small in some respects, it is necessary to exhaust the possibilities of association and cooperation - horizontally, vertically and crossborder to improve its performance. At the same time, when a unit is considered large in some respects, it is necessary to exhaust the possibilities for internal deconcentration and decentralization. on the other hand, administrative-territorial changes in geographical boundaries should be based on accurate research and assessments and in accordance with the opinion of the population [5].

\section{Guidelines for improving the administrative and territorial organization in Bulgaria}

Changes in the administrative and territorial structure are an important component of the environment, so the changes must have the necessary quality and focus. For example, there are several municipalities (Rhodopes, Maritsa, Tundzha and Dobrich), whose names do not meet the requirements of Article 7 (3) of the SASA - "The name of the municipality is the name of the settlement - its administrative center." Understanding that this is the smallest problem related to their functioning, the correctness presupposes a change in the SASBM, which allows for exceptions to this rule, unless action is taken related to their reorganization. Establishment or closure of municipalities due to "merger", "division", "accession" and "deletion" are forms that are not used in practice to carry out administrativeterritorial changes (ATP) at the municipal level. The use of some of these forms in the future should be encouraged by ensuring economic interest, using the tools available to the central government (eg relations with the national budget, access to resources from the Structural Funds, etc.). Significant changes and concretization of the conditions for the establishment of municipalities and respectively for the implementation of changes with them will contribute to this. To determine the order and manner of proving the observance of the requirement of art. 8 (1) item 5 for necessity of sufficient financial capacity for financing the expenses of the newly created municipality as well as to discuss the possibility for introduction of other conditions for the economic and financial potential of the created unit [6]. It is necessary to overcome the existing inequality of large settlements in connection with the possibility of creating areas in them - for those with a population over 300,000 people by law, and for those with a population over 100,000 - by decision of the municipal council. The organization on the territory of large cities is a matter of local importance and this implies full powers in this area of the municipal council. This would lead to the repeal of the Law on the Territorial Division of the Sofia Municipality and Large Cities and a change in the texts of the Spatial
Planning Act, as well as to increase its democracy and the possibility of decentralization of powers to municipal councils. Article 30 states that the change for the closure of town halls / districts is carried out in the order of their establishment, which means that a referendum must be held. With regard to the districts in the capital and the big cities, this provision creates difficulties, as it presupposes that an amendment to a law be requested for any change. According to the current provision, it also turns out that all closures of town halls have been carried out illegally so far, because in none of the cases a consultation of the people has been conducted, as the reason for the closure is legal - a change in the required population. town hall. This implies a complete rethinking of the texts related to the closure of the Independent Administrative and Territorial Units (SDUs). It would be possible for the closure of these units in case of non-fulfillment of the conditions for their establishment, when the population has no interest in such action and would not support a subscription or referendum, to be carried out administratively for a certain period of time. Related to the issue of closing down existing administrative units is the issue of creating them. Their main purpose is to provide better services to the population by decentralizing administration and services. On this basis, their creation should be within the exclusive competence of the municipal councils and / or the regional governor, and a consultation of the population should be carried out, but with the help of simpler forms of referendum and subscription. It is possible to envisage 6 months before the local elections on the proposal of the Municipal Councils the regional governor to issue an order to determine the mayoralties on the territory of the district for the next term. This will also imply the closure of those who do not meet the requirements of the law. It will be of practical use to specify the parameters for proving the possibility of performing functions provided by the municipality - a second condition for the establishment of a mayor's office. In order to promote the structuring of the territory of the municipalities and the creation of viable mayoralties with opportunities for providing access to the population.This means a greater volume of public services and ensuring operational autonomy through delegated budgets, the number of people to create town halls should be increased. The need to expand the conditions for the establishment of administrative units could be assessed with the introduction of a condition for road transport distance of the settlements to the mayor's office, financial efficiency, etc. following the logic of the provisions for the establishment of a municipality. Both units have a common goal - to provide public services at the lowest possible price in terms of local government [6]. 
In order to avoid preconditions for subjectivism and improvement of the legal framework, it is recommended to specify the conditions for creation of a new settlement. The closure of settlements is a problem because by law this is done in the order of creating grounds for a request by the population or by the mayor of the municipality. Mayors usually have no interest in closing settlements, and when they are depopulated or have no land or construction boundaries, there is no one to initiate the request by subscription. The possibility of closing the settlements administratively in the absence of a population with a permanent address should be discussed. Although declared unconstitutional in 1996, to rehabilitate the possibility of citizens' initiative to change the name of the settlement or, if the initiative is of an administrative structure (mayor's office, municipality, district, central government), to conduct a consultation with the local population. This presupposes the administration of the President of the Republic of Bulgaria, in whose powers is the name of the settlements to propose conditions and order for their change. There are no practices to confirm the existence of certain benefits for declaring a settlement a city (except for the norms for construction under the Spatial Development Act). The expediency of the change (especially the declaration of the resort settlements as a city) is relatively debatable, as the formal motives for it are related to the improvement of the development of the settlements, but this is the goal of each local administration, respectively each settlement, and the declaration of settlement. a place for a city would not help this process. Moreover, the vague benefits and subjective informal goals pursued in making this change largely predetermine the absence of a clearly defined effect. It is also appropriate to discuss who the decision-making body should be на село за град. Should this be within the competence of the Council of Ministers (CoM) or can this function be taken over by the Minister of Regional Development and Public Works, the regional governor or the municipal council. The settlement entity is present in the legislation without defining the specific benefits of its existence, and against the background of the other administrative units and territorial ones it is unconvincing. $\mathrm{He}$ questions of whether the place of this unit is in this law or in the Spatial Planning Act is debatable. By their nature, these are not territorial units because they are located in the territory of other urbanized territories such as settlements. It is right that the law on the settlement structure should regulate only the possibility for the settlement education to grow into a settlement when there is a permanent settlement of the population in it.

\section{CONCLUSION}

The administrative-territorial structure of our country had to be modern and effective, to give new content and develop local democracy, to strengthen the processes of decentralization, to ensure the formation of viable territorial communities and local authorities with strong powers and responsibilities. In the law on territorial organization as basic structural units on the territory of the country are again defined the municipalities and the districts and as constituent administrative-territorial units - the mayoralties and the regions. All administrative-territorial units are characterized by territory, borders, population and name. With the adoption of the legislation concerning the territorial organization came into force an extremely important legal framework containing formulated conditions and criteria for the formation of units subject to the law and relevant procedures, which made it a necessary regulator of the process of administrative-territorial organization. It contributed to the creation of administrative-territorial units working as close as possible to the population and made the process of functioning of local selfgovernment more efficient. In the conditions of real membership of Bulgaria in the European Union it is necessary to build the meso-level of government in the country. Thus, to transfer in practice the transfer of powers from the central to the regional administration, which will improve both the vitality of the regions and their centrifugal forces related to the effective management and development of the territories. During the period of work on the implementation of the administrative-territorial reform in the country, many other issues arose, some of which have not yet found their concrete and correct solution. In this direction we must strive to continue the process of improving the functional and institutional organization of local authorities and increasing the fiscal burden of municipalities in the state development of Bulgaria. This requires in the period 2021-2027 to implement in practice the construction of a new level of government in terms of continuing the process of decentralization to municipalities and districts, and above them to build the regional framework of the 6 planning regions. This issue raises the need for a new discussion and a new vision for the restructuring of the districts at the level of self-government. At least, because the nature and severity of administrative-territorial changes in Bulgaria need effective control over the activities of local authorities and the search for the right balance between development, planning, management and control. 


\section{REFERENCES}

1. Analytical report for development and improvement of the administrative - territorial structure of the country and its legal basis "NCTR" EAD, 2007;

2. Dokova, S. (2010) Territorial and administrative structure - Thrace - M;

3. Kovachev, Savin (2001) Administrative territorial structure of the Republic of Bulgaria;

4. Marinov, V. Al. Gildzhov, M. Hauser Review of the regional policy of Bulgaria in the process of accession to the European Union. Ed. FLGR 2001;

5. Petrov, K. Geoeconomic orientation of the planning regions in Bulgaria. Ed. Avangard Prima, 2008;

6. Ruseva Zlatka (2010) Review of the Bulgarian legislation related to local self-government and the administrative-territorial structure in the period 1879-1939;

7. Slaveykov PT Karastoyanov .. Portrait of the regions. Sofia, 2000. 